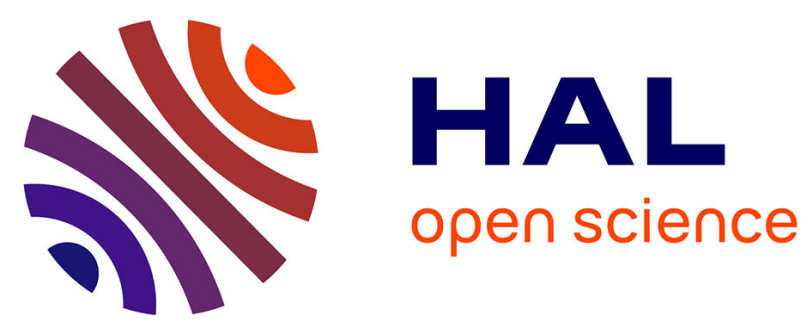

\title{
Actuator/sensor fault diagnosis for an experimental hot rolling mill - A case study
}

Didier Theilliol, Mahdi Mahfouf, Dominique Sauter, Jean-Christophe Ponsart

\section{To cite this version:}

Didier Theilliol, Mahdi Mahfouf, Dominique Sauter, Jean-Christophe Ponsart. Actuator/sensor fault diagnosis for an experimental hot rolling mill - A case study. IFAC Workshop on Automation in Mining, Mineral and Metal Industry, Sep 2006, CRACOW, Poland. pp.CDROM. hal-00095580

\section{HAL Id: hal-00095580 \\ https://hal.science/hal-00095580}

Submitted on 16 Sep 2006

HAL is a multi-disciplinary open access archive for the deposit and dissemination of scientific research documents, whether they are published or not. The documents may come from teaching and research institutions in France or abroad, or from public or private research centers.
L'archive ouverte pluridisciplinaire HAL, est destinée au dépôt et à la diffusion de documents scientifiques de niveau recherche, publiés ou non, émanant des établissements d'enseignement et de recherche français ou étrangers, des laboratoires publics ou privés. 


\title{
ACTUATOR/SENSORS FAULT DIAGNOSIS FOR AN EXPERIMENTAL HOT ROLLING MILL - A CASE STUDY
}

\author{
D. THEILLIOL $\left({ }^{\circ}\right)$, M. MAHFOUF $(+)$, D. SAUTER $\left({ }^{\circ}\right)$, J.C. PONSART $\left({ }^{\circ}\right)$ \\ (') Centre de Recherche en Automatique de Nancy - CNRS UMR 7039 \\ BP 239 - 54506 Vandoeuvre Cedex - France. \\ Phone: +33 383684465 - Fax: +33383684462 \\ (+) IMMPETUS - Department of Automatic Control and Systems Engineering \\ University of Sheffield, Sheffield S1 3JD, UK.
}

email: didier.theilliol@cran.uhp-nancy.fr

\section{INTRODUCTION}

Sensor or actuator failure, equipment fouling, feedstock variations, product changes and seasonal influences may affect controller performance and as many as $60 \%$ of industrial controllers problem (T.J. Harris et al., 1999). The diagnosis of such problems from raw data trends is often difficult, however model-based approach among fault diagnosis methods or Fault Detection and Isolation (FDI) techniques are considered and combined to supervise the process and to ensure reliability, availability, and safety in industrial.

The aim of a diagnosis procedure is to perform two main decision tasks: fault detection, consisting of deciding whether a fault has occurred or not, and fault isolation, consisting of deciding which element of the system has failed. The general procedure comprises the following three steps:

Residual generation: the process of associating, with the pair model-observation, features that allow to evaluate the difference with respect to normal operating conditions.

Residual evaluation: the process of comparing residuals to some predefined thresholds according to a test and at a stage where symptoms are produced.

Decision making: the process of deciding, based on the symptoms, which elements are faulty (i.e. isolation).

This implies the design of residuals that are close to zero in the fault-free situations while clearly deviating from zero in the presence of faults and that possess the ability to discriminate between all possible modes of faults, which explains the use of the term isolation. A short historical view on FDI can also be found in (Iserman and Ballé; 1997) and currents developments are reviewed in (Frank et al., 2000).

The main aim of this paper is to develop fault diagnosis technique for a Single Input Multiple Output (SIMO) system under disturbances when actuator/sensors faults occur simultaneously. The design is adapted to the hot rolling Hille mill of IMMPETUS (The Institute for Microstructural and Mechanical Process Engineering The University of Sheffield). The purpose of the hot rolling mill is to produce a steel plate from a preheated steel block at a specified thickness and desired mechanical and microstructual properties.. The plate thickness is reduced by pulling the plate between two parallel rolls at a specific rolling speed and temperature. The plate thickness is controlled by moving the upper work roll. For many years, several modern thickness control systems ((Grimble and Hearns., 1998), (Stephens and Randall, 1997)) have been designed to perform such a production, however only few research activities have been dedicated to consider a fault occurrence in the closed-loop and their consequence on the steel plate. Among the critical rolling process variables, such as the characteristic of mill drive, or the rolled slab, or the deformation temperature, the roll speed play an important role in the metal microstructure of the final product. This paper proposes to solve the problem of fault diagnosis in a speed control loop when actuator/sensors faults occur simultaneously. Based on a large diversity of advanced model-based methods for automated FDI, (Chen et al., 1999), (Gertler, 1998), the problem of actuator or/and sensor fault detection and magnitude estimation for linear time invariant systems can be defined as a basic one, nevertheless, it is not the case for the IMMPETUS hot rolling Hille mill. Indeed, due to difficulties inherent to the on-line identification in closed-loop systems, parameter estimation techniques are not suitable. With respect to parity space technique, this approach is suitable to distinguish between different faults in the presence of uncertain parameters, but not useful for fault magnitude estimation. Whereas, the observer-based method seems to be dedicated to our objective, the classical decoupled techniques such as Unknown Input Observer devoted to detect and to estimate faults (considered as unknown input) cannot fulfil our objective. As presented in Section III, because of the Unknown Input Observer design procedure, for the considered Single Input Multiple Output system with faults, the state decoupled from unknown input (fault) cannot be estimated correctly, due to observability problem and consequently is not enabled to generate accurate fault magnitude estimation. Hence, in order to reach our objective, a fault detection filter has been combined with a classical Luenberger observer. Fault detection filter gains are designed to have the filter residual in an invariant direction in the presence of an element from a set of a priori known faults. Based on an appropriate gain synthesis, an actuator fault detection filter is developed, inspired from (Keller, 1999), that makes it possible to detect and to estimate a particular and abrupt fault among disturbances which affect the rolled slabs. Combined with a conventional Luenberger observer, a software sensor design on the process can be defined through accurate state space estimation. While a single residual is sufficient to detect a fault, a set of structured residuals is required for fault isolation. In this context, in order to isolate and to estimate actuator/sensors faults which could occur simultaneously, a bank of coupled "fault detection filter - observer" is suggested and developed.

The paper is organized as follows. Section II describes the Hille Mill Single Input Multiple Output system and the actuator/sensor faulty state space representation. Section III is devoted to the specific fault detection filter design associated with a classical Luenberger observer in order both to detect, to estimate faults and disturbances, and in a second step the design of the bank of 
coupled "fault detection filter - observer" for an efficient fault isolation. Finally, simulation experiments are given in Section IV to illustrate the effectiveness and performance of fault diagnosis module. Conclusions and further work are discussed in Section V.

\section{THE HOT ROLLING HILLE MILL}

\subsection{Brief description}

The experimental hot rolling Hille mill, presented in Fig 1, is used to carry out multi-pass forward-forward or forward-reverse rolling and also complex multi-pass rolling experiments, has a three-phase $20 \mathrm{hp} 400 \mathrm{~V}, 50 \mathrm{~Hz}$ induction motor for main drive, an automatic control system for roll speed adjustment (between 1 60 rpm) and two rolls with a diameter of 139 mm. The maximum torque of the Hille mill at rated motor speed is $5800 \mathrm{Nm}$, and the maximum load of 50 tonnes. The roll gap is adjusted by a $3 \mathrm{hp}$ motor via a worm-wheel screw-down mechanism linked to the top roll. In this paper, particular attention is focused on the roll speed part. the mechanical configuration of the experimental hot rolling Hille mill sketches with three mass as the motor, the reduction gear and the rolls.

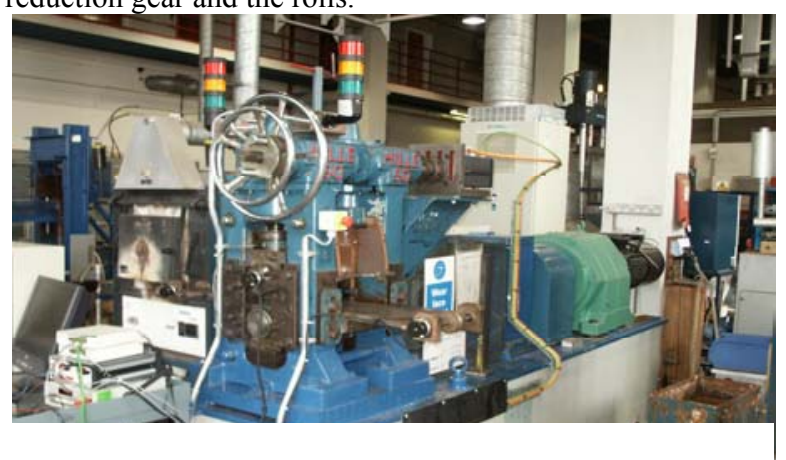

Fig. 1. Hille mill mechanical configuration.

The main feedback roll speed control is based on a cascade control structure with an inner current/torque control loop and an outer speed control loop. The electromechanical torque is the natural response of the motor to compensate any torsional force applied in its shaft and it is directly related with the Hille mill rotational system. The motor drive module, incorporating advanced motor control (closed-loop vector control), ensures the command following ability of the motor drive torque. As illustrated in Fig. 2, based on the roll torque estimation performed by a multilayer neural network model (Mahfouf et al., 2005), a feedforward control loop is cancelling its effects upon the roll speed to achieve a fast speed response and to have better disturbance rejection ability coming from the load torque fluctuation during rolling.

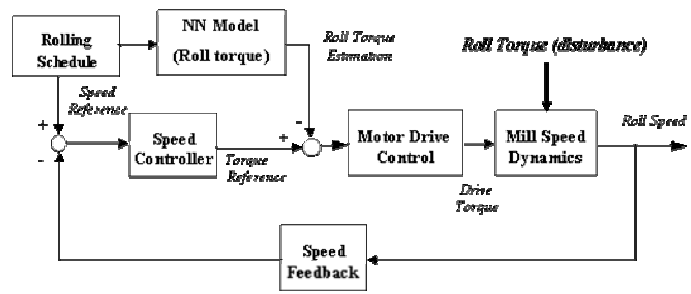

Fig. 2. A block diagram of the roll speed control loop.

\subsection{Roll speed modeling}

A traditional way of developing the roll speed model is to divide the rolling mill into several mechanical components coupled by flexible shafts, and then to develop the motion equations using Newton's law. In this case by applying Newton's motion law, the rotational system is represented by the following equations:

$$
\begin{aligned}
& J_{m} \frac{d \omega_{m}}{d t}=-\mu_{m} \omega_{m}-T_{s h m}-T_{e} \\
& T_{s h m}=K_{s h m}\left(\frac{d \omega_{m}}{d t}-\frac{d \omega_{g}}{d t}\right)
\end{aligned}
$$




$$
\begin{aligned}
& J_{g} \frac{d \omega_{g}}{d t}=-\mu_{g} \omega_{g}+T_{s h m}-\frac{T_{s h r}}{R_{g}} \\
& T_{s h r}=K_{s h r}\left(\frac{1}{R_{g}} \frac{d \omega_{g}}{d t}-\frac{d \omega_{r}}{d t}\right) \\
& J_{r} \frac{d \omega_{r}}{d t}=-\mu_{r} \omega_{r}-T_{s h r}-T_{\text {load }}
\end{aligned}
$$

where $\omega, J$ and $\mu$ are the speed, inertia and friction coefficient of the motor $(m)$, gear $(g)$ and roll $(r)$ shafts respectively, $R_{g}$ is the gear box ratio (constant during experiment), $T_{\text {load }}$ is the torque applied to the rolls when a slab is rolled, $T_{s h m}$ and $T_{s h r}$ are the strain torque of the motor and roll shaft respectively. The model parameters, such as the inertia, the stiffness of the shafts and the frictions of the individual components are supposed to be known and constant (Mahfouf et al., 2005).

According to the sensors available on the experimental hot rolling Hille mill, a roll speed discrete state space representation can be established as follows:

$$
\begin{aligned}
x_{k+1} & =\mathrm{A} x_{k}+\mathrm{B} u_{k}+\mathrm{D} d_{k} \\
y_{k} & =\mathrm{C} x_{k}
\end{aligned}
$$

where $x=\left[\begin{array}{lll}\omega_{m} & \omega_{r} & T_{s h r}\end{array}\right]^{T}$ is the state space vector, $u=T_{e}$ is the input vector, $d=T_{\text {load }}$ in the non measurable disturbance (unknown input) with $\mathrm{D}$ its associated and constant distribution matrix, and $y=x$ is the output vector. An accurate sampling period equal to $0.001 \mathrm{~s}$ according to the dynamic performance in closed-loop has been determined to calculate the various matrices.

Due to abnormal mill operation or to simply material aging, actuator faults can occur in the overall system. An actuator or sensor fault can be represented by additive and/or multiplicative faults as follows:

$$
z_{j}^{f}=\alpha_{k} z_{j}+z_{0}
$$

where $z_{j}$ and $z_{j}^{f}$ represent the $j^{\text {th }}$ normal and faulty control actions if $z_{k}=u_{k}$ or faulty sensor if $z_{k}=y_{k}$, respectively. $z_{0}$ denotes a constant offset and $0 \leq \alpha_{k} \leq 1$ denotes a gain degradation of the $j^{\text {th }}$ component (constant or variable). Therefore, in faulty case, the roll speed discrete state space representation becomes as:

$$
\begin{aligned}
x_{k+1} & =A x_{k}+B u_{k}+F_{a} f_{k}^{a}+D d_{k} \\
y_{k} & =C x_{k}+F_{s} f_{k}^{s}
\end{aligned}
$$

where $F$ represents the fault distribution matrix and $f$ is the faulty vector with index " $a$ " for actuator, respectively " $s$ " for sensor.

Let us define in the next section the fault detection block and the bank of fault detection modules involved in order to solve the problem of the actuator/sensors fault diagnosis.

\section{ACTUATOR/ SENSORS FAULT DIAGNOSIS}

\section{1 residual generator definition: filter-observer tandem design}

As a first step, only actuator faults will be considered and represented as an additive unknown input term in the following discrete dynamic equation:

$$
\begin{aligned}
x_{k+1} & =A x_{k}+B u_{k}+F_{a} f_{k}^{a} \\
y_{k} & =C x_{k}
\end{aligned}
$$

where $x \in \mathfrak{R}^{n}$ is the state vector, $y \in \mathfrak{R}^{m}$ is the output vector, $u \in \mathfrak{R}^{p}$ is the input vector and $f^{a} \in \mathfrak{R}^{q}$ is the actuator fault vector. $A, B, C$, and $F_{a}$ are known matrices with appropriate dimensions. In the following, the number of faults is assumed to be less than the number of states, such that:

$$
\operatorname{rank}\left(C F_{a}\right)=\operatorname{rank}\left(F_{a}\right)=q \leq m
$$

Therefore, if $(C, A)$ is observable, a conventional stable observer can detect the fault by monitoring the residual $(r=y-\hat{y}$ with $\hat{y}$ defines estimated output). A more challenging task is to estimate also the fault magnitude as well as the state-space vector: an Unknown Input Observer can achieve this main objective. Under necessary and sufficient conditions, defined in the book by (Chen et al., 1999), an unknown input (considered as a fault) full-order observer can be written as follows: 


$$
\begin{aligned}
w_{k+1} & =\mathrm{E} w_{k}+\mathrm{TB} u_{k}+\mathrm{K} y_{k} \\
\hat{x}_{k} & =w_{k}+\mathrm{H} y_{k}
\end{aligned}
$$

where $\hat{x}$ is the estimated state vector and $w$ is the state of this full-order observer. $\mathbf{E}, \mathbf{T}, \mathbf{K}$ and $\mathrm{H}$ are matrices to be designed for achieving unknown input decoupling requirements. That is to say, the state estimation error vector $(e=\hat{x}-x)$ of the observer goes to zero asymptotically, regardless of the presence of the unknown input in the system. The unknown input observer design is achieved by solving the following equations:

$$
\begin{aligned}
& (\mathrm{HC}-\mathrm{I}) F_{a}=0, \\
& \mathrm{~T}=\mathrm{I}-\mathrm{HC}, \\
& \mathrm{E}=\mathrm{A}-\mathrm{HCA}-\mathrm{K}_{1} \mathrm{C}, \\
& \mathrm{K}_{2}=\mathrm{EH}, \\
& \mathrm{K}=\mathrm{K}_{1}+\mathrm{K}_{2},
\end{aligned}
$$

If

$$
(C, A-H C A) \text { is observable, }
$$

an Unknown Input Observer exist.

The estimation error vector and the residual vector are calculated from (41) as follows:

$$
\begin{aligned}
& e_{k+1}=\left(A-\mathrm{K}_{1} C\right) e_{k}+F_{a} f_{k}^{a} \\
& r_{k}=C e_{k}
\end{aligned}
$$

Moreover, through an appropriate Singular Value Decomposition, see (Theilliol et al., 2002), accurate fault magnitude estimation is generated. If (47) is not fulfilled, (Chen et al., 1999) have proposed a solution based on canonical decomposition procedure, However, a reduced-order observer is established and the decoupled state vector is not completely estimated. Consequently, as already shown in (Theilliol et al., 2006), a fault detection filter is considered where the gain $K_{1}$, with $T=I$ and $H=0$, is synthesized such that the residual vector $r_{k}=y_{k}-C \hat{x}_{k}$ is insensitive to $f_{k}^{a}$, but the projectors $R$ are designed such that the projected residual vector $q_{k}=R r_{k}$ is sensitive only to a particular fault direction. Hence, the system, defined in (41), can be expressed with $K_{1}=K_{A}+K_{C}$ as follows:

$$
\begin{aligned}
\hat{x}_{k+1} & =\mathrm{A} \hat{x}_{k}+\mathrm{B} u_{k}+\left(\mathrm{K}_{\mathbf{A}}+\mathrm{K}_{\mathrm{C}}\right)\left(y_{k}-C \hat{x}_{k}\right) \\
\hat{y}_{k} & =\mathrm{C} \hat{x}_{k}
\end{aligned}
$$

where $\mathrm{K}_{\mathrm{A}}$ should be defined in order to obtain $A F_{a}-\mathrm{K}_{\mathrm{A}} C F_{a}=0$ and:

$$
\mathrm{K}_{\mathrm{A}}=\omega \Xi
$$

with $\omega=A F_{a}$ and $\Xi=\left(C F_{a}\right)^{+}$

where $\mathrm{K}_{C}$ should be defined in order to obtain $\mathrm{K}_{C} C F_{a}=0$ and:

$$
\mathrm{K}_{\mathrm{C}}=K \Psi
$$

where $\Psi=\beta\left(I_{m}-\left(C F_{a}\right)\left(C F_{a}\right)^{+}\right)$.

it must be noted that $\beta$ is chosen as a matrix composed of 1's with $\beta \in \mathfrak{R}^{m-q . m}$. Compared to (Keller, 1999) in the stochastic case, no other conditions are needed. With respect to $K$, this reduced gain defines the unique free parameter in this specific filter and will be synthesized in a common way.

Based on (51) and (52), (50) becomes equivalent to the following:

$$
\hat{x}_{k+1}=(\overline{\mathrm{A}}-K \overline{\mathrm{C}}) \hat{x}_{k}+\mathrm{B} u_{k}+\mathrm{K}_{\mathrm{A}} y_{k}+K \Psi y_{k}
$$

$$
\hat{y}_{k}=\mathrm{C} \hat{x}_{k}
$$

with $\bar{A}=A\left(I_{m}-F_{a} \Xi C\right)$ and $\bar{C}=\Psi C$. The gain $K$ is synthesised by a common eigenstructure assignment such that $(\overline{\mathrm{A}}-K \overline{\mathrm{C}})$ is Hurwitz.

The gain decomposition $K_{1}=K_{A}+K_{C}$ and associated definitions involve the following matrices properties: 


$$
\Xi C F_{a}=0 \text { and } \Psi C F_{a}=I
$$

and make possible the generation of projected residual vector as follows:

$$
q_{k}=R r_{k}=\left[\begin{array}{c}
\Psi \\
\Xi
\end{array}\right] r_{k}=\left[\begin{array}{c}
\Sigma \bar{r}_{k} \\
\Xi \bar{r}_{k}+f_{k-1}^{a}
\end{array}\right]=\left[\begin{array}{l}
\gamma_{k} \\
\eta_{k}
\end{array}\right]
$$

As suggested by (Theilliol et al., 2006), the vector $\eta \in \mathfrak{R}^{q}$ should be directly exploited for fault detection. Indeed, a residual evaluation algorithm can be performed by the direct fault magnitude evaluation through a statistical test in order to supervise the process. To achieve the purpose of an accurate vector estimation, (Sauter et al., 2005) have proposed the handling of matrices via an on-line inversion operation. Here, another solution is adopted as follows:

the fault detection filter works in tandem with a conventional Luenberger observer estimator. Based on a very simple idea, under the schedule of $\gamma_{k}$ residual evaluation, the available $\eta_{k}$ fault estimation is injected as a separate known input in Luenberger observer, such that:

$$
\begin{aligned}
\hat{x}_{k+1} & =\mathrm{A} \hat{x}_{k}+\mathrm{B} u_{k}+\mathrm{K} y_{k}+F \eta_{k} \\
\hat{y}_{k} & =C \hat{x}_{k}
\end{aligned}
$$

Based on this technique, a system defined in (38) could be represented as in (39) by an augmented unknown input vector such that:

$$
F_{a}=\left[\begin{array}{ll}
D & F_{a}
\end{array}\right]
$$

If the conditions (40) and (54) are fulfilled, the fault detection filter should be used to detect the actuator fault and to estimate both the fault magnitude as well as the disturbance based on the vector $\eta$. Fig. 3 illustrates the different elements involved in the filter-observer tandem.

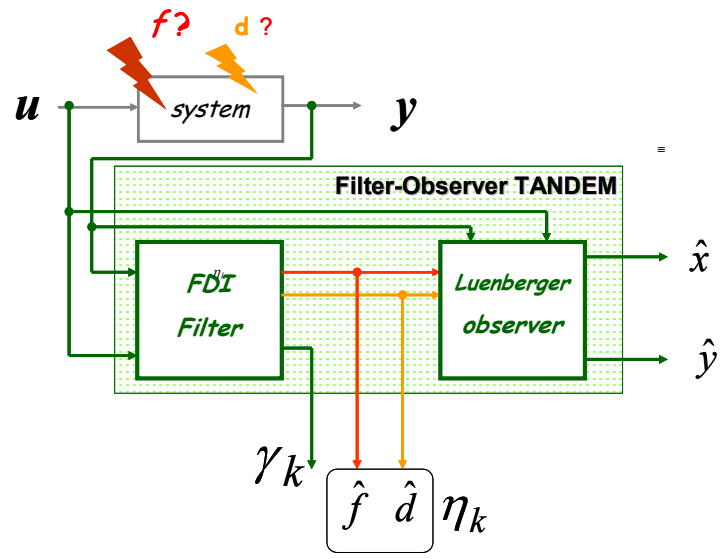

Fig. 3. A block diagram of the filter-observer tandem.

However, under the assumption than an actuator fault and a sensor fault can occur simultaneously, as represented in (38), condition (40) is not fulfilled: $(m+q)$ faults need to be considered in the filter-observer tandem synthesis. The $(m+q)$ faults compromise the fault isolation established with a unique filter-observer tandem. In the next paragraph, a solution is proposed to perform the fault isolation in this context.

\subsection{Fault isolation design.}

For the purpose of fault diagnosis, the basic idea of the approach is to reconstruct the state of the system from the subsets of measurements. The objective is to build a bank of filter-observer tandems so that each of these filters is driven by all inputs and all outputs except the $j^{\text {th }}$ measurement variable. $y_{j}$ is not used in the $j^{\text {th }}$ filter-observer tandem due to the fact that $y_{j}$ is assumed to be corrupted by the fault and therefore does not carry the relevant information (Frank, 1990). For the synthesis of the filterobserver tandem, the following discrete state space equation is involved:

$$
\begin{aligned}
x_{k+1} & =A x_{k}+B u_{k}+F_{a} f_{k}^{a} \\
z_{k}^{j} & =\bar{C}^{j} x_{k}
\end{aligned}
$$

where $\forall j \in[1 \cdots m], z_{k}^{j} \in \mathfrak{R}^{m-1}$ is the output vector without the $j^{\text {th }}$ element and $\bar{C}^{j}$ is the $C$ matrix without the $j^{\text {th }}$ row which correspond to a column of $F_{s}$ matrix ((37)). 
This fault diagnosis scheme is similar to the well known Generalized Observer Structure (GOS) but the absence of a sensor fault. In order to reach both the isolation and the estimation of an actuator fault under disturbances, we also consider the case where $j=0$ : the filter-observer tandem is based on system (9) which $\mathrm{c}$ is not related to the sensor fault-free case.

Under the assumption that $\forall j \in[1 \cdots m],\left(\bar{C}^{j}, A\right)$ is observable, the bank could be designed following the scheme presented in figure 4.

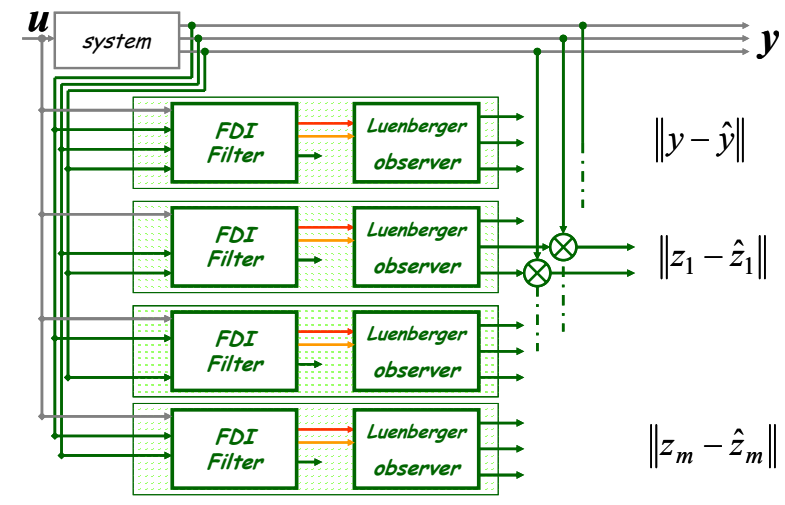

Fig. 4. A block diagram of the fault diagnosis structure.

As in the classical approach, a residual evaluation which involves statistical testing such as the limit checking test, the generalized likelihood ratio test, or the trend analysis test is performed for each filter-observer tandem of the bank described before. An output vector of the statistical test can be built according to a test applied to a set of $\mathrm{m}+1$ residuals. The status of the residuals is equal to " 0 " when the residual signal is close to zero in some sense and equal to " 1 " otherwise.

The bank of filter-observer tandems generates an incidence matrix as follows where each column is called the coherence vector associated to each fault signature:

Table 1. Incidence matrix

\begin{tabular}{cccccc}
\hline Fault & $F_{a}$ & $F_{a}$ & $F_{a}$ & $\bullet \bullet$ & $F_{a}$ \\
& $\& \overline{\mathrm{F}}_{\mathrm{a}}$ & $\&$ & $F_{s}^{1}$ & $\&$ & $F_{s}^{2}$ \\
$\|y-\hat{y}\|$ & 0 & 1 & 1 & 1 & $\& F_{s}^{m}$ \\
\hline$z_{1}-\hat{z}_{1} \|$ & 0 & 0 & 1 & 1 & 1 \\
$\left\|z_{2}-\hat{z}_{2}\right\|$ & 0 & 1 & 0 & 1 & 1 \\
$\bullet \bullet$ & 0 & 1 & 1 & 0 & 1 \\
$\left\|z_{m}-\hat{z}_{m}\right\|$ & 0 & 1 & 1 & 1 & 0 \\
\hline
\end{tabular}

Therefore, without $\left(\overline{\mathrm{F}}_{\mathrm{a}}\right)$ or only the actuator faults $\left(F_{a}\right)$, the bank of filter-observer tandems generates some zero mean residuals. Otherwise, the filter-observer tandem, insensitive to a sensor fault $\left(F_{j}\right)$, is easily isolated based on the GOS structure, irrespective of the actuator fault occurrence. Decision making is then realized according to an elementary logic (Leonhardt and Ayoubi, 1997) which can be described as follows: a fault indicator is equal to one if the residual vector generated by the bank is equal to a column of the incidence matrix and is equal to zero otherwise. The element which is associated with the indicator being equal to one is then declared to be faulty.

\section{SIMULATION RESULTS}

For illustration purposes, different scenarios have been conducted under simulation environment This simulation platform describes the rolling process behavior of the Hille mill without affecting the real plant.

In the study, the roll torque $T_{\text {load }}$ is supposed non measurable as on the real plant. Hence, the following model-based roll speed is used to estimate the actuator fault $f$, roll torque unknown input $T_{\text {load }}$ and state space vector $x=\left[\begin{array}{lll}\omega_{m} & \omega_{r} & T_{s h r}\end{array}\right]^{T}$ :

$$
x_{k+1}=\mathrm{A} x_{k}+\mathrm{B} u_{k}+\underbrace{\left[\begin{array}{ll}
F & D
\end{array}\right]}_{\widetilde{F}} \underbrace{\left[\begin{array}{c}
f_{k} \\
T_{\text {load }}
\end{array}\right]}_{\widetilde{f}}
$$

For the experimental hot rolling Hille mill, conditions (40) and (54) are fulfilled, the bank of filter-observer tandems is tested in fault-free and faulty cases. 


\subsection{Fault-free case}

Various step responses of the roll speed subsystem are studied and disturbances are considered. Without an actuator fault, all simulations are performed for a four-rolling multi-pass operations with a first roll speed at $30 \mathrm{rpm}$ and $5 \mathrm{rpm}$ less at each step, together with a reduction of $10 \%$ starting at $40 \%$. From the simulation results of Fig. 5, it is apparent that under a classical PID control the roll speed responses are close to the reference and ensure an accurate performance despite the roll torque force. The disturbances for each step simulate roll pass (see the zoomed part in Fig. 5). In the fault-free case, all residual vectors are equal to zero means (not presented here). Fig. 6 shows the performance of the fault detection filter to estimate an exact roll torque $T_{\text {load }}$ through the second component of vector $\eta_{k}$ generated by the $0^{\text {th }}$ filter-observer tandem.

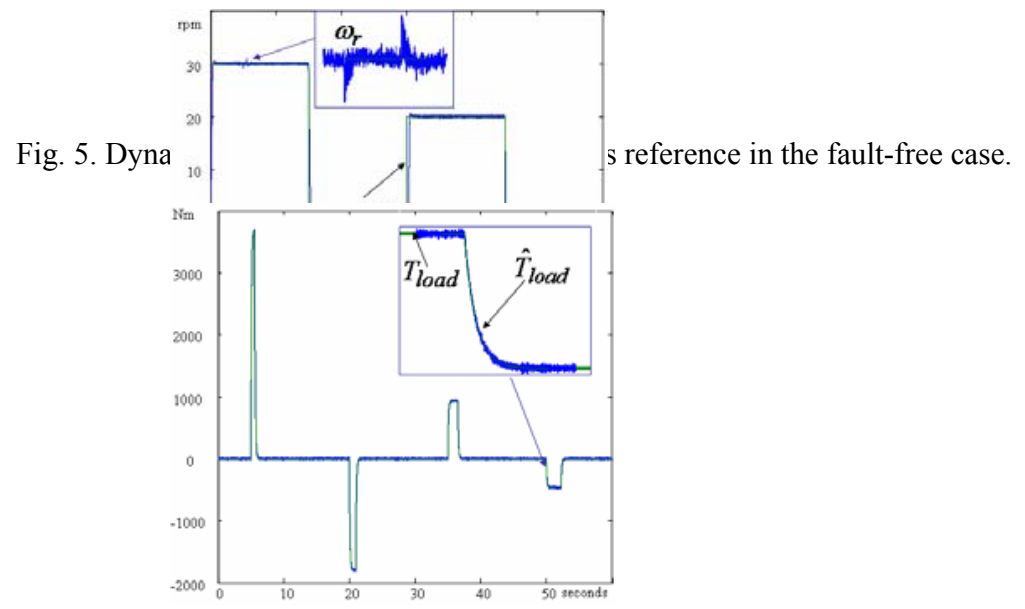

Fig.6. Roll torque and its estimation with $y=x$.

4.2 Actuator faulty case

A gain degradation of the motor due to material ageing or a failure in a component equivalent to $50 \%$ loss of effectiveness is supposed to occur at instant $2 \mathrm{~s}$ just before the first rolling and to disappear at time 30 s during a step. To do so without damaging the system, the control input applied to the system is equal to the control input computed by the controller multiplied by a constant system $\left(\alpha=0.5\right.$ and $\left.\mathrm{u}_{0}=0\right)$. The consequence of an actuator fault on the speed control loop is illustrated in Fig. 7 with a zoom presented in Fig 8. Despite the fault, the effect is not significant in the steady state due to the motor drive control strategy based on drive torque, as illustrated in Fig. 7. However, since an actuator fault acts on the system as a perturbation, and due to the presence of the integral error in the controller, the system outputs reach again their nominal values when the slab is presented to the rolling process (see Fig. 7). Compared to the dynamic behaviour in the fault-free case, see Fig. 5, the actuator fault affects the experiment and needs to be detected on-line.

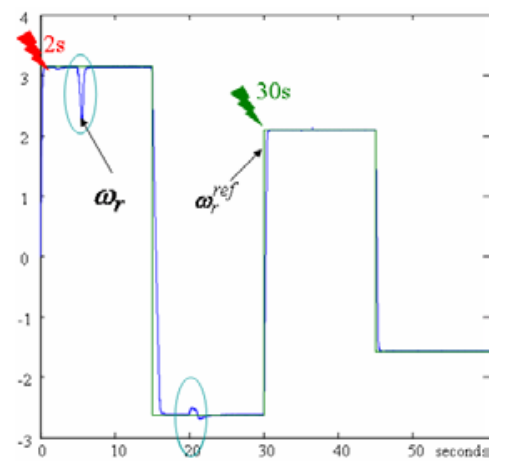

Fig. 7. Dynamic behaviour of Roll speed and its reference in the faulty case

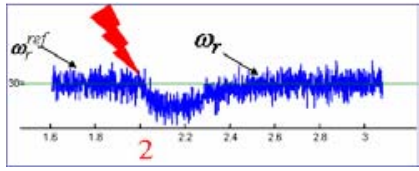


Fig. 8. Zoom of Fig 7 around the fault occurrence at 2 s.

Similarly to the fault-free case, the filter-observer tandem, which is synthesized with all the measurement, provides a residual vector equal to zero means and accurate state space vector (not presented here). An important feature of the filter-observer tandem is the capability to generate an accurate fault estimation. As illustrated in Fig. 9 (and associated zoom in Fig 10), the fault estimation $\hat{f}^{a}$ is close to zero in the fault-free case and is close to the fault magnitude, represented by $\alpha \times u_{k}$, when the failure has occurred. The simulation results show that the actuator fault detection filter is very effective in detecting and estimating the fault magnitude under disturbances constraints for the whole operating conditions. The fault magnitude estimation should be evaluated through a classical statistical threshold test in order to generate alarms for the operating system.

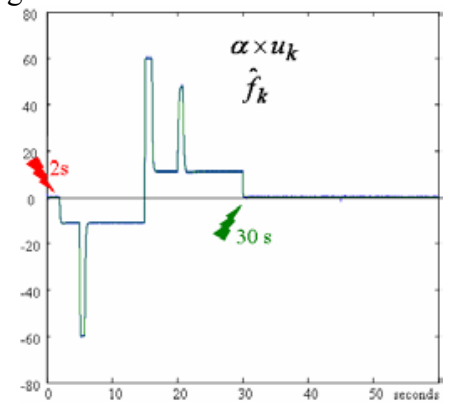

Fig. 9. Fault magnitude estimation and "real" fault with $50 \%$ loss of effectiveness.

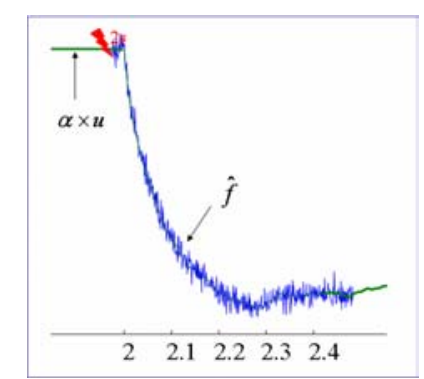

Fig. 10. Zoom of Fig 9 around the fault occurrence at 2 s.

\subsection{Actuator and sensor faults case}

In addition with an actuator fault similar as previously, a sensor fault on the speed motor $\omega_{r}$ (which it is involved in the closed loop vector) is supposed to occur at instant $10 \mathrm{~s}$ and disappear at instant 30s. As defined in (37), a constant gain on the speed motor $\omega_{r}$ is created and added with $\alpha=0$ and $y_{0}=0.3 \mathrm{rpm}$. This bias can be observed in Fig 11. The control law tries to cancel the static error created by the corrupted output. Consequently, the real output is different from the reference input.

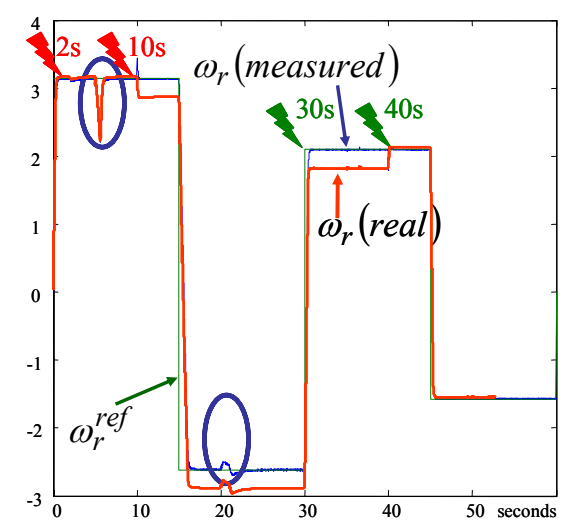

Fig. 11. Dynamic behaviour of the real Roll speed and the measured Roll speed with its reference in the faulty case

According to the incidence matrix defined in the previous section, only the filter-observer tandem synthesized with all measurement except the speed motor $\omega_{r}$ provides a residual vector equal to zero means. Under noisy conditions, an accurate roll torque magnitude estimation (second component of the vector $\widetilde{f}$ in (60)) and actuator fault estimation are performed by the fault 
detection filter, as presented in the previous paragraph. The difference between the real and the estimation $\omega_{r}$ illustrates the performances of the method which provides an accurate state space vector: the residual vector is equal to zero mean, as presented in Fig 12. The developed technique provides an accurate $\hat{\omega}_{r}$ insensitive to sensor fault, and actuator fault under disturbances.

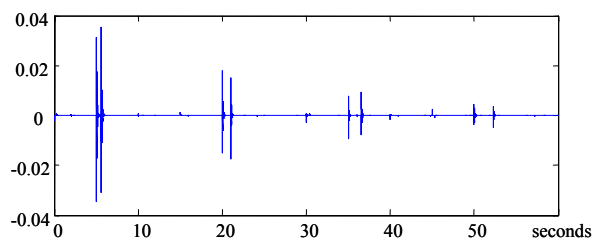

Fig. 12. Difference between the real and the estimation $\omega_{r}$.

\section{CONCLUSION}

There have been a number of techniques developed over the past decade for fault detection and isolation in various systems. In this paper, the proposed FDI method, developed first for a specific application, does not require the complex handling matrices when the UIO reduced-order observer needs to be built for specific properties. However, through its simple fault detection filter working in tandem with a conventional Luenberger observer, the developed technique has proved to be effective for FDI under actuator and sensors faults as well as being robust against disturbances. Using an appropriate bank of "filter-observer tandems", the proposed fault diagnosis strategy represents an efficient tool in the operator's decision hot rolling mill process.

\section{REFERENCES}

Chen J., and R.J. Patton (1999) Robust model-based fault diagnosis for dynamic systems. Kluwer academic publishers.

Frank, P.M., S.X. Ding and B. Köppen-Seliger (2000) Current developments in the theory of FDI. In: Safeprocess'2000 IFAC Symposium, Budapest, Hungary, vol. 1, pp. 16-27.

Gertler J.J. (1998). Fault detection and diagnosis in engineering systems. Marcel Dekker, Inc. New York Basel Hong Kong.

Grimble M.J. and G. Hearns. (1998), LQG Controllers for state-space systems with pure transport delays: application to Hot strip mills, Automatica, vol. 34, n¹0, pp. 1169-1184.

Harris T.J., Seppala C., Desborough L.D., (1999). A review of performance monitoring and assessment techniques for univariate and multivariate control systems. Journal Process of Control, vol. 9, pp. 1-17.

Isermann R., and P. Ballé, (1996), Trends in the application of model based fault detection and diagnosis of technical processes. $13^{\text {th }}$ Triennal World Congress IFAC, San Francisco, USA, pp.1-12.

Keller J.Y. (1999), Fault isolation filter design for linear stochastic systems. Automatica, vol. 35, pp. 1701-1706.

Leonhardt S. and M. Ayoubi, "Methods of fault diagnosis", Control Engineering and Practice, vol. 5, pp. 683-692, 1997.

Liu B. and Si J. (1997), Fault isolation filter design for linear time-invariant systems. IEEE Transactions on Automatic Control, vol. 42, n5, pp. 704-707.

Mahfouf M., Y. Yang, M.A. Gama, D.A. Linkens (2005), Roll Speed and Roll Gap Control with Neural Network Compensation, The Iron and Steel Institute of Japan International, Vol. 45, No. 6, pp. 841-850.

Sauter D., H. Jamouli, J.Y. Keller, J.C. Ponsart (2005), Actuator fault compensation for a winding machine, Control Engineering Practice, Vol. 13, No. 10, pp. 1307-1314.

Stephens R.I. and Randall A. (1997), On-line adaptive control in the hot rolling of steel, IEE Proceeding Control Theory and Applications, Vol. 144, no. 1.

Theilliol D., Noura H., Ponsart J.C. (2002). Fault diagnosis and accommodation of a three-tank system based on analytical redundancy. ISA Transactions, Vol. 41, No. 3, pp. 365-382.

Theilliol D., Mahdi M, Sauter D., Gama M.A. (2006). Actuator fault detection isolation method and state estimator design for hot rolling mill monitoring. 6e IFAC Symposium on Fault Detection Supervision and Safety for Technical Processes SAFEPROCESS, Beijing, China,. 